\title{
Evaluation of sonographic measurement of umbilical cord coiling index in the second trimester and its correlation to perinatal outcome
}

\author{
Naglaa Ali M. Hussein ${ }^{1 *}$ and Mohammed H. El Refaey ${ }^{2}$ \\ ${ }^{1}$ Assistant professor of Obstetrics and Gynecology, Faculty of Medicine. Tanta University, Tanta. Egypt. \\ ${ }^{2}$ Lecturer of Diagnostic Radiology, Diagnostic Radiology Department. Faculty of Medicine. Tanta University, Tanta. Egypt.
}

*Corresponding author: Naglaa Ali Mohammed Hussein, Assistant Professor of Obstetrics and Gynecology, Faculty of Medicine. Tanta University, Tanta. Egypt.

Received date: July 07, 2021; Accepted date: July 15, 2021; Published date: August 09, 2021

Citation: Naglaa A. M. Hussein, Mohammed H. E. Refaey, (2021) Evaluation of sonographic measurement of umbilical cord coiling index in the second trimester and its correlation to perinatal outcome J.Obstetrics Gynecology and Reproductive Sciences 5(6) DOI:10.31579/2578-8965/088

Copyright: () 2021, Naglaa Ali M. Hussein, This is an open access article distributed under the Creative Commons Attribution License, which permits unrestricted use, distribution, and reproduction in any medium, provided the original work is properly cited.

\begin{abstract}
The umbilical cord represents a unique lifeline between the fetus and mother and contains two arteries and one vein wrapped up in Wharton's jelly with moderate twists. Umbilical coiling abnormalities can result in fetal growth restriction, fetal distress, or intrauterine fetal death.

Hypocoiled umbilical cords are associated with intrauterine fetal death (IUFD), fetal growth restriction, fetal distress, low Apgar scores, fetal congenital anomalies, and abnormal insertion of the umbilical cord. Hypercoiled umbilical cords are associated with IUFD, fetal distress, asphyxia, fetal congenital anomalies, and the presence of a single umbilical artery. The aim of this work is to determine if the umbilical Cord coiling index measurement during second trimester ultrasound scan can predict perinatal outcome. Seventy eight healthy uncomplicated pregnant women who regularly attended the antenatal care clinic for antenatal care and to do anomaly ultrasound scan on her baby in 2nd trimester.

All participants were informed about the aims and the procedures of the study and signed an informed consent form prior to beginning.

Regular antenatal care visit was done every two weeks till delivery with assessment of perinatal outcomes regarding: gestational age at delivery, fetal monitoring by CTG, method of delivery, meconium staining amniotic fluid or not, examination by apgar score at $1^{\mathrm{st}}$ and $5^{\text {th }}$ minute, birth weight, admission to NICU or not and perinatal death.

According to umbilical cord index, of total 78 pregnant women who completed the study 62 (79.2\%) were having normal UC coiling, 10 of cases $(12.8 \%)$ were having hypocoiling and $6(7.7 \%)$ were having hypercoiling.

Our results showed that hypo- and hyper-coiling were associated with increased incidence of preterm labor (32-36 weeks) " $22.2 \%$ and $40 \%$ respectively" while normo-coiling was associated with lesser incidence " $2 \%$ ". Both hypocoiling " $10 \% "$ and hypercoiling "16.7\%" groups showed higher incidence of IUGR when compared with the normocoiling group "1.6\%". APGAR score at minute one was significantly lower in the both hypocoiling and hypercoiling groups than the normocoiling group with p-value: 0.005 . While at minute five, there was no significant difference between the three groups of the study. Conclusion: The abnormal umbilical coiling index " $<10$ th percentile or $>90$ th percentile" is associated with adverse perinatal outcomes. Therefore, early evaluation on Umbilical cord Index in the $2^{\text {nd }}$ trimester can identify fetuses who are at risk and thus help in further management.
\end{abstract}

Keywords: umbilical cord; intrauterine fetal death; hypo- and hyper-coiling

\section{Introduction}

The umbilical cord is vital for development, wellbeing and survival of the fetus and it is vulnerable to kinking, compression, traction and torsion, which may affect the perinatal outcome [1].
Vessels of the umbilical cord have a spiral course (pass along the length of the cord in helical fashion). This is called "coiling" of the umbilical cord, which changes as pregnancy advances [2]. 
A coil is defined as a completed 360 spiral course of umbilical vessel around warton jelly. The umbilical cord coils by the umbilical cord in length in centimeter and called "index of twist" [3].

As measurement of the total length of the cord is not feasible prior to birth, Strong et al simplified calculation of the cord coiling and named it "the umbilical cord coiling index" (UCI). It is calculated as the reciprocal of the length of one complete coiling in centimeters measured antenatally by ultrasound [4].

Abnormal cord coiling index include both hypocoiled cord (cord with abnormal cord coiling index which is below 10th percentile) and hypercoiled cords "cord with an umbilical cord coiling index which is more than 90th percentile" [5].

The cause, role and mechanism of umbilical cord coiling have not been elucidated; nonetheless, it has been shown that hypocoiled or hypercoiling of the umbilical cord during 2 nd trimester is associated with adverse perinatal outcome such as intra uterine fetal death, intrauterine growth restriction, pre-term labor and fetal distress during labor; consequently, with increased delivery of a lowbirth-weight fetus and admission to the neonatal intensive care unit [6].

\section{Aim of the work}

The aim of this work is to determine if the umbilical Cord coiling index measurement during second trimester ultrasound scan can predict perinatal outcome.

\section{Patients and Methods}

\section{Technical Design}

This study was Cross-sectional study carried out at Antenatal Care Clinic in Obstetrics and Gynecology Department, Tanta University Hospital. Seventy-eight healthy uncomplicated pregnant women who regularly attended the antenatal care clinic for antenatal care. at the period from January 2019 to January 2020.

Before the start of the study, permission was obtained from the Institutional Review Board "IRB" and Ethical Committee in the faculty of medicine, Tanta University. Also Informed consent from participants included in the study was obtained.

\section{Inclusion Criteria:}

Before the start, Approval for this study will be received from the Ethics Committee of the University Tanta Faculty of Medicine, Moreover, written informed consent was obtained from the patients who participated in the study.

\section{Inclusion criteria}

The participants in this study were selected according to the following criteria:

1) Gestational age at 22 weeks to 26 weeks with regular antenatal care visits till delivery.

2) Uncomplicated singleton pregnancy.

\section{EXCLUSION CRITERIA}

All patients had history of any of the following were excluded:

1) Multiple pregnancies, polyhydramnios and Oligohydramnios.

2) Ultrasonographically detected fetal anomalies or

3) Umbilical cord anomalies.
4) Pregnancy complications including hypertension, antepartum hemorrhage and other medical diseases.

5) Women who escaped regular antenatal care visit.

6) Prolonged or obstructed labor.

\section{Operational Design:}

Methods

The selected participants will be subjected to the followings:

I. Full detailed medical history will be taken including the following points:

- Personal history: Name, Age, occupation, address, special habits, parity, No. of kids, Primary or secondary infertility.

- Present and past history: of any medical diseases

- Menstrual and Obstetric history:

- Age of menarche, Regularity of the cycle and its durations, and Last menstrual period,

- Expected date of delivery.

- Gravidity, parity and pregnancy outcome.

- Any complication during pregnancy, labor or puerperium.

- For each labor ask about gestational age at delivery, mode of delivery and neonatal outcome.

- For each abortion if present, the gestational age when it occurred, mode of termination, and occurrence of any complication must be recorded.

- Family history: systemic diseases, congenital anomalies and history of twins.

\section{Clinical Examination:}

Including Full General and Abdominal Examination

- The general condition and appearance.

- Body mass index (BMI)

- Vital signs (blood pressure, te mperature, pulse rate and respiratory rate).

- Neck (thyroid, cervical LN and congested neck veins)

- Abdominal examination:

- Inspection any abnormalities or pigmentation,

- Palpate fundal level, any tenderness or rigidity.

\section{IV.Laboratory Investigations:}

The following laboratory investigations for all participants in the study (done at the Ain shams university Hospitals Laboratories):

\section{- $\quad$ CBC, Kidney, Liver Function tests and fasting \& Postprandial Blood Sugar (FBS \& PPS).}

\section{- Ultrasonography:}

Ultrasonographic examination at $22-26$ GA was done by one investigator using AB 2-7 convex abdominal probe on Voluson 730 Pro Machine (Ge Healthcare, Austria). 


\section{Examination will include:}

1. Biometric measurements: to assess gestational age, fetal growth, and expected fetal weight.

\section{Exclusion of fetal, umbilical or placental anomalies.}

3. Umbilical cord coiling index: will be measured by the method suggested by Degani et al (2015):

The distance, in centimeter, between two adjacent coils of umbilical artery will be measured from the right outer surface of vascular wall to the right outer surface of its next twist. The coiling index is defined as the reciprocal of the measured distance.

Cases whose umbilical cord coiling index is lower than 10th percentile $(<0.1$ coils $/ \mathrm{cm})$ are defined as having Hypocoiled cord, cases whose index is between 10th \& 90th percentile (0.1-0.3 coils/cm) are defined as having Normocoiled cords \& cases whose index is more than 90 th percentile $(0.3$ coils $/ \mathrm{cm})$ are defined as having Hypercoiled cords (according to Strong et al.,1994). (7)

Frequency of follow up visit will be every 2 weeks till delivery.

\section{V.Assessment Of Pregnancy Outcome:}

1. Gestational age at time of delivery.

2. Fetal monitoring by CTG.

3. Method of delivery.

4. Meconium staining amniotic fluid or not.

5. Newborn examination for Apgar score at first \& fifth minute and neonatal birth weight.

6. Neonatal admission to intensive care unit.

7. Perinatal death

\section{Study design:}

This study will be approved from Tanta University Institutional Review Board (IRB).

\section{VI.Statistical Analysis}

All statistical calculation were done using computer program SPSS (statistical package for social science; SPSS Inc., Chicago, IL, USA) version 15 for Microsoft Windows.

\section{Results}

The percentage of patients who completed the study were $88.6 \%$ (78/88), while only $11.4 \%$ were withdrawn (10/88) from the study. Of these 10 cases, 4 were excluded because of preeclampsia, 2 were excluded because gestational DM, 1 was excluded because of traffic accident, and the 3 cases were excluded because they didn't attend the antenatal care.

The 78 cases that had completed the study were classified according to the UCI by using ultrasound (at gestational age 22: 26weeks) into; $79.2 \%$ (62/78) were diagnosed to be normocoiling, $12.8 \%$ (10/78) were diagnosed as hypocoiling, and the rest 6 cases in percentage of $7.7 \%$ were diagnosed as hypercoiling. There was not a statistically significant difference between the three groups of the study as regard parity. On the other hand, the majority of the normocoiling group patients were $<35$ while the majority of other two group were $\geq 35$ years. The association between the groups regarding this classification was statistically highly significant with p-value: $\mathbf{0 . 0 0 1}$. There is no statistically significant difference between the three groups of the study as regard gestational age, fetal weight at time of examination (22: 26 weeks) and Amniotic fluid index.

There is no statistically significant difference between the three group

groups of the study as regard IUFD, IUGR and fetal heart rate abnormalities (fetal distress) during antenatal follow up visit.

One IUFD in each of three group occurred during follow up and those patients were excluded from the following tables.

There was a high statistically significant difference between the three groups of the study as regard mode of delivery showing higher rates of Cesarean section in hypocoiling and hypercoiling groups than in the normocoiling group with p-value: $<\mathbf{0 . 0 0 1}$. There is also a statistically significant difference between the 3 groups as regard gestational age at delivery with p-value: 0.009 .

As regard the perinatal outcomes of the three groups of the study, there was a statistical significant difference between them as regard.

APGAR score minute one with p-value: 0.005 with higher rate in the hypocoiling and hypercoiling groups. Also, there was a high statistical significant difference between the studied groups as regard need for Neonatal ICU admission with $\boldsymbol{p}$-value: $<\mathbf{0 . 0 0 1}$ with higher rate in the hypocoiling and hypercoiling groups.

1- Asphyxia: lack of gas exchange, which is considered in the presence of fetal acidosis ( $\mathrm{ph}<7$ ), a 5- min Apgar score of 0-3 (altered tone, depressed level of consciousness, seizures) and other multiple organ system signs.

2- peri natal period: immediately before and after birth, it start at the $20^{\text {th }}$ to $28^{\text {th }}$ week of gestation and ends 1 to 4 weeks after birth.

\begin{tabular}{|c|c|c|c|c|c|c|c|c|}
\hline \multirow[t]{2}{*}{ Variable } & \multicolumn{2}{|c|}{ Normocoiling } & \multicolumn{2}{|c|}{ Hypocoiling } & \multicolumn{2}{|c|}{ Hypercoiling } & \multirow{2}{*}{$\begin{array}{c}\mathrm{F} \\
\text { value }\end{array}$} & \multirow{2}{*}{$\begin{array}{c}\mathbf{P} \\
\text { value }\end{array}$} \\
\hline & \multicolumn{2}{|c|}{$\begin{array}{c}\text { mean } \pm \text { SD } \\
(\text { range })\end{array}$} & \multicolumn{2}{|c|}{$\begin{array}{c}\text { mean } \pm \text { SD } \\
(\text { range })\end{array}$} & \multicolumn{2}{|c|}{$\begin{array}{c}\text { mean } \pm \text { SD } \\
(\text { rang })\end{array}$} & & \\
\hline \multirow[t]{2}{*}{ Parity } & \multicolumn{2}{|c|}{$1.27 \pm 0.5$} & \multicolumn{2}{|c|}{$1.5 \pm 0.2$} & \multicolumn{2}{|c|}{$1.8 \pm 0.4$} & 2.1 & 0.1 \\
\hline & \multicolumn{2}{|c|}{$(0-4)$} & \multicolumn{2}{|c|}{$(1-2)$} & \multicolumn{2}{|c|}{$(1-3)$} & & \\
\hline Variable & $\mathrm{No}=62$ & $\%$ & No $=10$ & $\%$ & $\mathrm{No}=6$ & $\%$ & $\chi^{2}$ & $\mathrm{P}$ \\
\hline \multicolumn{9}{|l|}{$\begin{array}{l}\text { Maternal age } \\
\text { (years): }\end{array}$} \\
\hline$<35(65)$ & 59 & 90.7 & 4 & 6.1 & 2 & 3.2 & & \\
\hline$\geq 35(13)$ & 3 & 23.1 & 6 & 46.2 & 4 & 30.2 & 16.6 & $<0.001 * *$ \\
\hline
\end{tabular}

* p-value $<0.05$ is significant

$* *$ p-value $<0.01$ is highly significant

$X^{2}$ : chi-square test

F: anova test

Table (1): Comparison between the studied groups regarding maternal 


\begin{tabular}{|c|c|c|c|c|c|c|c|c|}
\hline \multirow[t]{2}{*}{ Variable } & \multicolumn{2}{|c|}{ Normocoiling (62) } & \multicolumn{2}{|c|}{ Hypocoiling (10) } & \multicolumn{2}{|c|}{ Hypercoiling (6) } & \multirow{2}{*}{$\begin{array}{l}\mathrm{F} \\
\text { value }\end{array}$} & \multirow{2}{*}{$\begin{array}{c}\mathrm{P} \\
\text { value }\end{array}$} \\
\hline & \multicolumn{2}{|c|}{ mean $\pm \mathrm{SD}($ range $)$} & \multicolumn{2}{|c|}{$\begin{array}{c}\text { mean } \pm \mathrm{SD} \\
(\text { range })\end{array}$} & \multicolumn{2}{|c|}{$\begin{array}{c}\text { mean } \pm \mathrm{SD} \\
\text { (range) }\end{array}$} & & \\
\hline Gestational age (weeks) & \multicolumn{2}{|c|}{$24.6 \pm 1.9$} & \multicolumn{2}{|c|}{$24.6 \pm 2.1$} & \multicolumn{2}{|c|}{$24.2 \pm 0.94$} & 0.14 & 0.8 \\
\hline Fetal weight (gram) & \multicolumn{2}{|c|}{$562.9 \pm 184$} & \multicolumn{2}{|c|}{$560.3 \pm 182.3$} & \multicolumn{2}{|c|}{$559.4 \pm 112$} & 0.8 & 0.4 \\
\hline Variable & $\mathrm{No}=62$ & $\%$ & $\mathrm{No}=10$ & $\%$ & $\mathrm{No}=6$ & $\%$ & Test & P Value \\
\hline \multicolumn{9}{|c|}{ Amniotic fluid index (AFI): } \\
\hline Average & 62 & 100 & 10 & 100 & 6 & 100 & & \\
\hline $\begin{array}{l}\text { Oligo, poly } \\
\text { hydramnios }\end{array}$ & 00 & 0.0 & 00 & 0.0 & 0 & 11 & 1 & 1 \\
\hline
\end{tabular}

Table (2): Comparison between the studied groups regarding fetal sonographic parameters at time of examination (22: 26 weeks)

\begin{tabular}{|c|c|c|c|c|c|c|c|c|}
\hline \multirow[t]{2}{*}{ Variable } & \multicolumn{2}{|c|}{ Normocoiling } & \multicolumn{2}{|c|}{ Hypocoiling } & \multicolumn{2}{|c|}{ Hypercoiling } & \multirow[t]{2}{*}{$\chi^{2}$} & \multirow[t]{2}{*}{$\mathrm{P}$} \\
\hline & $\mathrm{No}=62$ & $\%$ & No $=10$ & $\%$ & No $=6$ & $\%$ & & \\
\hline \multicolumn{9}{|c|}{ Intrauterine growth restriction } \\
\hline Yes & 1 & 1.6 & 1 & 10 & 1 & 16.7 & \multirow[t]{2}{*}{4.5} & \multirow[t]{2}{*}{0.1} \\
\hline No & 61 & 98.4 & 9 & 90 & 5 & 83.3 & & \\
\hline \multicolumn{9}{|c|}{ Fetal H.R abnormalities } \\
\hline Yes & 2 & 3.2 & 2 & 20 & 1 & 16.7 & \multirow[t]{2}{*}{1.5} & \multirow[t]{2}{*}{0.4} \\
\hline No & 60 & 96.8 & 9 & 90 & 5 & 83.3 & & \\
\hline \multicolumn{9}{|c|}{ Intrauterine fetal death } \\
\hline Yes & 1 & 1.6 & 1 & 10 & 1 & 16.7 & \multirow[t]{2}{*}{1.5} & \multirow[t]{2}{*}{0.4} \\
\hline No & 61 & 98.4 & 9 & 90 & 5 & 83.3 & & \\
\hline
\end{tabular}

Table (3): Comparison between the studied groups regarding antenatal care and fetal affection during antenatal follow up visit.

\begin{tabular}{|c|c|c|c|c|c|c|c|c|}
\hline \multirow[t]{2}{*}{ Variable } & \multicolumn{2}{|c|}{ Normocoiling } & \multicolumn{2}{|c|}{ Hypocoiling } & \multicolumn{2}{|c|}{ Hypercoiling } & \multirow[t]{2}{*}{$\chi^{2}$} & \multirow[t]{2}{*}{$\mathrm{P}$} \\
\hline & $\mathrm{No}=61$ & $\%$ & $\mathrm{No}=9$ & $\%$ & $\mathrm{No}=5$ & $\%$ & & \\
\hline \multicolumn{9}{|l|}{ Mode of delivery } \\
\hline Vaginal & 40 & 65.6 & 1 & 11.1 & 0 & 0.0 & \multirow[t]{2}{*}{22.8} & \multirow[t]{2}{*}{$<0.001 * *$} \\
\hline $\begin{array}{c}\text { C.S. } \\
\end{array}$ & 4 & 34.4 & 8 & 88.9 & 5 & 100 & & \\
\hline \multicolumn{9}{|l|}{ Meconium staining } \\
\hline Yes & 4 & 6.6 & 3 & 33.3 & 2 & 40 & \multirow[t]{2}{*}{1.7} & \multirow[t]{2}{*}{0.4} \\
\hline No & 57 & 93.4 & 6 & 66.7 & 3 & 60 & & \\
\hline \multicolumn{9}{|c|}{ Gestational age at delivery } \\
\hline Full Term & 59 & 96.7 & 7 & 77.8 & 3 & 60 & \multirow[t]{2}{*}{9.4} & \multirow[t]{2}{*}{0.4} \\
\hline Pretern & 2 & 3.3 & 2 & 22.2 & 2 & 40 & & \\
\hline \multicolumn{9}{|c|}{ Fetal heart rate abnormality during labor } \\
\hline Yes & 2 & 3.3 & 2 & 22.2 & 2 & 40 & \multirow[t]{2}{*}{1.3} & \multirow[t]{2}{*}{0.5} \\
\hline No & 59 & 96.7 & 7 & 77.8 & 3 & 60 & & \\
\hline
\end{tabular}

* p-value $<0.05$ is significant

$* *$ p-value $<0.01$ is highly significant

$x^{2}$ : chi-square test

Table (4): Comparison between the studied groups regarding intrapartum characteristics

\begin{tabular}{|c|c|c|c|c|c|c|c|c|}
\hline \multirow[t]{2}{*}{ Variable } & \multicolumn{2}{|c|}{ Normocoiling } & \multicolumn{2}{|c|}{ Hypocoiling } & \multicolumn{2}{|c|}{ Hypercoiling } & \multirow[t]{2}{*}{$\chi^{2}$} & \multirow[t]{2}{*}{$\mathrm{P}$} \\
\hline & No=61 & $\%$ & No $=9$ & $\%$ & $\mathrm{No}=5$ & $\%$ & & \\
\hline \multicolumn{9}{|l|}{ Asphyxia } \\
\hline Yes & 1 & 1.6 & 1 & 11.1 & 1 & 20 & \multirow[t]{2}{*}{4.5} & \multirow[t]{2}{*}{0.1} \\
\hline No & 60 & 98.4 & 8 & 88.9 & 4 & 80 & & \\
\hline \multicolumn{9}{|c|}{ APGAR score minute one } \\
\hline Normal 7:10 & 56 & 91.8 & 5 & 55.6 & 3 & 60 & \multirow[t]{2}{*}{14.8} & \multirow[t]{2}{*}{$0.005^{*}$} \\
\hline Low $<7$ & 5 & 8.2 & 4 & 44.4 & 2 & 40 & & \\
\hline \multicolumn{9}{|c|}{ APGAR score minute five } \\
\hline Normal 7:10 & 59 & 96.7 & 8 & 88.9 & 4 & 80 & \multirow[t]{2}{*}{7.4} & \multirow[t]{2}{*}{0.1} \\
\hline Low $<7$ & 2 & 3.3 & 2 & 22.2 & 2 & 40 & & \\
\hline \multicolumn{9}{|l|}{ NICU } \\
\hline Yes & 2 & 9.9 & 3 & 33.3 & 2 & 40 & \multirow[t]{2}{*}{24.3} & \multirow[t]{2}{*}{$<0.001 * *$} \\
\hline No & 59 & 96.7 & 7 & 77.8 & 3 & 60 & & \\
\hline Perinatal death & & & & & & & & \\
\hline
\end{tabular}




\begin{tabular}{|c|c|c|c|c|c|c|c|c|}
\hline Yes & 00 & 0.0 & 1 & 11.1 & 1 & 20 & 2.5 & 0.3 \\
\hline No & 61 & 100 & 8 & 88.9 & 4 & 80 & & \\
\hline \multicolumn{9}{|c|}{ Small for gestational age } \\
\hline Yes & 00 & 0.0 & 1 & 11.1 & 1 & 20 & 2.5 & 0.3 \\
\hline No & 61 & 100 & 8 & 88.9 & 4 & 80 & & \\
\hline
\end{tabular}

$*$ p-value $<0.05$ is significant.

$* * *$ p-value $<0.01$ is highly significant.

$* X^{2}$ : chi-square test

$*$

Table (5): Comparison between the studied groups regarding perinatal outcome

\section{Discussion}

The umbilical cord is a very important structure connecting the placenta and the fetus. It consists of 3 blood vessels, and it has the characteristic of screw-shaped coils. The cause, role and mechanism of umbilical cord coiling have not been elucidated; nonetheless it has been shown that the coiling level is associated with adverse perinatal outcome such as intrauterine fetal death, intrauterine growth restriction and fetal distress during labor [8].

Many studies have been carried out evaluating the relationship between UCI and various maternal and fetal outcomes though majority of them have been based on the postnatal UCI. Both hypocoiling and hypercoiling have been linked to various adverse perinatal outcomes [8].

In the light of these studies and keeping in mind the need for further evaluation of the credibility of the antenatal umbilical coiling index, this study was planned to assess the role of the antenatal umbilical coiling as a predictor of adverse perinatal outcome.

According to umbilical cord index, our results showed that of the 78 pregnant women participating in this study, 62 women " $79.5 \%$ " showed normocoiling, 10 women " $12.8 \%$ " showed hypocoiling, while 6 women "7.7\%" showed hypercoiling.

These results were in agree with that of Patil et al., (2019) who reported in there study on 200 pregnant women that 156 cords "78\%" showed normal coiling, 23 "11.5\%" showed hypocoiling, and 21 " $10.5 \%$ " showed hypercoiling [9].

Mittal et al., (2015) found similar results on their study on 200 pregnant women with uncomplicated, singleton pregnancy. They found hypocoiled -UCI $<10^{\text {th }}$ percentile $(\mathbf{9 \%})$; normocoiled- with UCI between $10^{\text {th }}-90^{\text {th }}$ percentile $(\mathbf{8 1 \%})$ and hypercoiled- UCI $>90^{\text {th }}$ percentile $\mathbf{( 1 0 \% )}$ [10].

Also, the study of Adesina et al., (2017) on the umbilical cords of 436 neonates showed that Normal UCI was observed in $351 \mathbf{( 8 0 . 5 \% )}$ neonates, $44(\mathbf{1 0 . 4 \%})$ and $41(\mathbf{9 . 1 \%})$ neonates had hypo- and hypercoiled cords, respectively [11].

The participating women in our study were divided according to the UCI into three groups: normocoiling, hypocoiling, and hypercoiling groups. And further statistical analysis was done on these three groups and our results showed.

As regard maternal age, our results showed that maternal age in normocoiling group was lower than in the other two groups with significant difference between them "p-value: 0.002" as shown in table (2). And when compared between the three groups as regard age $<$ or $>35$ old we found also a statistical significant difference with $p$-value $<0.001$ indicating that abnormal umbilical cord coiling was common in women $>35 \mathrm{ys}$.

In harmony with our results was Chitra et al., (2012) as they reported that they found in their study on one thousand antenatal women an association between elderly gravida ( $>35$ years) and both hypocoiled and hypercoiled $(P=0.041$ and $P=0.003$, resp. $)$ [12].

While Adesina et al., (2017) was against our results and reported that there was there was no statistically significant difference when maternal age, parity and gestational age were compared in the hypocoiled, normocoiled and hypercoiled groups [11].

As regard parity, our results showed that there was no statistically significant difference between the groups of the study with p-value: 0.1.

These results go in harmony with Adesina et al., (2017) as they reported no statistically significant difference when compared parity in their three groups of the study [11].

Also, Patil et al., (2019) reported that on comparing UCI with parity, it was found that there was no statistical significance between primigravida and multigravida [9].

As regard gestational age, at first visit our results showed no significant difference between all groups of the study with p-value: 0.8 .

But when we measured the effect of UC coiling abnormalities, our results showed that hypo- and hyper-coiling were associated with increased incidence of preterm labor " $22.2 \%$ and $40 \%$ respectively" while normocoiling was associated with lesser incidence " $2 \%$ ".

These results go in agree Jo et al., (2018) who reported on their retrospective study of 251 pregnancies in which a fetal anatomic survey with a recorded UCI was performed at 22-28 weeks gestation that there was no significant difference between the three groups of their study as regard gestational age at first evaluation. And as regard preterm delivery both hypocoiling and hypercoiling groups shows higher incidence of preterm delivery " $36.4 \%$ and $16.7 \%$ respectively" than the normocoiling group " $7.7 \%$ with $(\mathrm{p}=0.041)[8]$.

Against these results was Ohno et al., (2016) who reported on their retrospective study, 200 consecutive umbilical cords, that there was no significant difference between the three groups of the study as regard gestational age at birth and incidence of preterm labor [13].

As regard fetal birth weight, at first visit our results showed no significant difference between the three groups of the study with p-value:

0.4. Revaluation of fetal birth weight at delivery time showed also no significant difference between the three groups of the study with pvalue:

0.09 despite that both hypo and hypercoiling groups were associated with lower birth weight than the normocoiling guop. 
These results go in harmony with Mittal et al., (2015) who reported that Out of the 200 newborn babies, 12 weighed less than 2,500 gm, i.e., were low birth weight babies. Three babies out of these belonged to the hypocoiled group and four belonged to the hypercoiled group. Both hypo- and hypercoiling were found to be significantly associated with low birth weight with $\mathrm{p}$-value " 0.0344 between hypocoiling group and normocoiling group and p-value: 0.0095 between hypercoiling and the normocoiling group". This may well be explained by the increased number of preterm deliveries in the hypocoiled group and a higher number of small for gestational age babies in the hypercoiled group.

While, Jo et al., (2019) found a significant difference between the three groups of the study as regard the incidence of neonates with low birth weights and the incidence in the hypocoiled and hypercoiling groups was $36.4 \%$ and $20 \%$ respectively, which was significantly greater than the normocoiled groups "10\%" with $(\mathrm{p}=0.044)$ [8].

However, Kashanian et al. (2016) and de Laat et al. (2017) noted overcoiling and low weight at birth to be significantly related. [14, 15]

As regard the amniotic fluid index, our results showed that there was no significant difference between the three groups of the study with "pvalue: $1.0 "$.

The results of Jo et al., (2018) showed also no significant difference between their three groups as regard amniotic fluid index [8].

We studied the effect of umbilical cord coiling index abnormalities on fetal outcomes, and we found the following results.

As regard intrauterine growth restriction "IUGR", our results showed no statistically significant difference between the three groups of the study with p-value: 0.1. Both hypocoiling and hypercoiling groups showed higher incidence of IUGR when compared with the normocoiling group with percentage of $10 \%$ and $16.7 \%$ vs $1.6 \%$ [8].

Similar to our results were in agree with Jo et al., (2018) who found also no significant difference between their study groups as regard incidence of IUGR in both hypocoiling and hypercoiling group vs the normocoiling group " $20 \%$ and $25 \%$ vs $9.3 \%$ " [8].

Against our results was Dakshayini and Meghna, (2020) who found a significant difference between their three groups " $p$ : 0.003". The higher incidence of IUGR was found in their study in hypercoiling and normocoiling groups " $73.3 \%$ and $49.3 \%$ " while it was lowest in the hypocoiling group " $8.3 \%$ " [16].

Also, Patil et al., (2019) was against our results as they found a statistically significant difference between their groups "p: $<0.001$ " and the higher incidence in the hypercoiling group " $81 \%$ " while both normocoiling and hypocoilig groups showed the lowest incidence " $3.2 \%$ and $0.0 \% "$ as regard IUGR [9].

Also, our results showed no significant difference as regard intrauterine fetal death "IUFD" with similar distribution to that in IUGR with p-value: 0.4 .

As regard abnormalities of fetal HR, our results showed no significant difference between the three studied groups neither during pregnancy nor during labor with p-value: 0.4 and 0.5 respectively.

As regard mode of delivery, our results show a significant difference between the groups with p-value: $<0.001$. Both hypocoiling and hypercoiling groups showed higher incidence of cesarean section "CS" than the normal vaginal delivery " $88.9 \%$ and $100 \%$ vs $11.1 \%$ and $0.0 \%$ " while the normocoiling group showed higher incidence of vaginal delivery than CS " $65.6 \%$ vs $34.4 \%$ ".
These results were in agree with Patil et al., (2019) who found also a significant difference between the three groups of the study " $p$ value: 0.08 " with higher incidence of CS in both hypo and hyper-coiling groups while the normo-coiling group showed higher incidence of vaginal delivery [9].

As regard meconium staining of then amniotic fluid, our results showed no significant difference between the three groups of the study with p-value: 0.4 . However, this non-significant difference both hypo- and hyper- coiling groups showed higher incidence of meconium staining the normo-coiling group " $33.3 \%$ and $40 \%$ Vs 6.6\%".

Similar to these results Mittal et al., (2015) found no significant difference between hypocoiling, hypercoiling and normocoiling groups as regard meconium staining of amniotic fluid with p-value "1.000 and 0.300 respectively" [10].

Also, Predanic et al., (2017) found that meconium staining of amniotic fluid was observed more frequently in the group of hypoand hyper-coiled cords (25.8\% [8/31 fetuses] and 22.2\% [6/27 fetuses], respectively) rather that in the normocoiled group of subjects $(13.1 \%$ [31/236 fetuses]). This, however, was not statistically significant $(\mathrm{P}=$

.212, chi-squared test; degrees of freedom, 3.107, 2) [17].

As regard fetal asphyxia, our results showed no significant difference between the three studied groups with p-value: 0.1 .

De Laat et al. (2016 a and b) found hypercoiled to be significantly associated with birth asphyxia-acute and chronic [18].

As regard APGAR score, at minute one our results showed that there was a significant statistical association "p-value: 0.005 " between the three group of our study with higher incidence of low scores with hypocoiling and hypercoiling groups " $44.4 \%$ and $40 \%$ vs $8.2 \%$ in normocoiling group". While at $5 \mathrm{~min}$, our results showed no significant association "p-value: 0.1 " between the three group of our study with higher incidence of low scores with hypocoiling and hypercoiling groups " $11.1 \%$ and $20 \%$ vs $3.3 \%$ in normocoiling group".

Devaru and Thusoo, (2018) found a similar significant association as regard APGAR score at 1 min with p-value: $<0.001$, but he found also a significant association at APGAR score at $5 \mathrm{~min}$ with $\mathrm{p}$-value 0.025 which was against our results [19].

The result of Mittal et al., (2015) was against our result at APGAR score at $1 \mathrm{~min}$ as he found no significant association between their study groups but was agree with ours as regard APGAR score at $5 \mathrm{~min}$ with no significant association was found and reported in general that there was no association between poor APGAR scores and umbilical cord coiling abnormalities [10].

Jo et al., (2018) was also against our results as regard APGAR score at $1 \mathrm{~min}$ as they found no significant association between their study groups [8].

Adesina et al., (2017) was agree with our results as regard APGAR at $5 \mathrm{~min}$ as they found no significant association between their study groups with p-value: 0.201 [11].

As regard the need for neonatal ICU admission, our results showed significant association between the three studied groups with value: $<0.001$ with higher incidence in both hypocoiling and hypercoiling groups vs the normocoiling group " $33.3 \%$ and $40 \%$ vs $9.9 \%$ ".

Our results were in agree with Patil et al., (2019) as they found a significant association in the hypocoiling and hypercoiling groups and NICU admission when compared with the normocoiling group with p-value: $<0.001$ with higher incidence of NICU admission in the 
hypo coiling and hypercoiling groups vs the normocoiling group " $43.5 \%$ and $28.6 \%$ vs $12.2 \%$ " [9].

Against our result was Mittal et al., (2015) who found no significant association between their both hypocoiling and hypercoiling groups vs the normocoiling group as regard NICU admission with pvalue: 1.000 . in this study no NICU admission was recorded in the hypocoiling and hypercoiling groups while 3 cases were recorded in the

nornociling group [15].

Also, Adesina et al., (2017) found no significant difference between was observed in their study as regard NICU admission with p-value: $0.976[11]$.

\section{Conclusion}

The abnormal umbilical coiling index " $<10^{\text {th }}$ percentile or $>90^{\text {th }}$ percentile" is associated with adverse perinatal outcomes. Therefore, early evaluation on Umbilical cord Index in the $2^{\text {nd }}$ trimester can identify fetuses who are at risk and thus help in further management

\section{Reference}

1. Machin GA, Ackerman J and Gilbert-Barness E (2020): Abnormal umbilical cord coiling is associated with adverse perinatal outcomes. Pediatr Dev Pathol; 3: 462-71.

2. Ercal T, Lacin S, Altunyurt S, Saygili U, et al. (2018): Umbilical Coiling Index: is it a marker for the fetus at risk? Br J Clin Pract;50:254-256

3. Devaru D and Thusoo M. (2020): Umbilical Coiling Index \& the Perinatal Outcome. J Obstet Gynaecol India; 62(1): 43-46.

4. Degani S, Lewinsky RM, Berger H. et al (2015): Sonographic estimation of umbilical coiling index and correlation with Doppler flow characteristics. Obstet Gynecol; 86: 990-993.

5. Degani D and Meghna T. (2011): Umbilical Coiling Index \& the Perinatal Outcome. The Journal of Obstetrics and Gynecology of India 62(1):43-46.

6. Patil N, Kulkarni S, Lohitashwa R. (2019): Umbilical Cord Coiling Index and Perinatal Outcome. J Clin Diagn Res. 7(8):
1675-1677.

7. Strong TH, Jones KL, Benirschke K. (2014): The umbilical cord twist: origin, directions, and relevance. Am J Obstet Gynecol. 1987;157: 833-8.

8. Jo Y, Jang D, Lee G. (2018): The Sonographic Umbilical Cord Coiling in Late Second Trimester of Gestation and Perinatal Outcomes. Int J Med Sci. 2011; 8(7): 594-598.

9. Patil N, Kulkarni S, Lohitashwa R. (2019): Umbilical Cord Coiling Index and Perinatal Outcome. J Clin Diagn Res. 7(8): 1675-1677.

10. Mittal A, Nanda S, Sen J. (2015): Antenatal umbilical coiling index as a predictor of perinatal outcome. Arch Gynecol Obstet. 291;4, pp:763-768

11. Adesina K, Ogunlaja O, Olarinoye A, et al. (2017): An observation of umbilical coiling index in a low risk population in Nigeria. J. Perinat.

12. Chitra T, Sushanth Y, and Raghavan S. (2012): Umbilical Coiling Index as a Marker of Perinatal Outcome: An Analytical Study. Obstet Gynecol Int.

13. Ohno Y, Terauchi M, Tamakoshi K. (2016): Perinatal outcomes of abnormal umbilical coiling according to a modified umbilical coiling index. J Obstet Gynaecol Res. 2016 Nov;42(11):14571463.

14. Kashanian M, Akbariana A, Kouhpayehzadeh J (2016): The umbilical coiling index and adverse perinatal outcome. Int $\mathbf{J}$ Gynecol Obst 95:8-13.

15. de Laat MW, van Alderen Elise D, Franx A et al (2017): The umbilical coiling index in complicated pregnancy. Obstet Gynecol Surv 62:357-358

16. Dakshayini D and Meghna T. (2020): Umbilical Coiling Index $\&$ the Perinatal Outcome. The Journal of Obstetrics and Gynecology of India 62(1):43-46.

17. Predanic M and Perni SC. (2017): Absence of a relationship between umbilical cord thickness and coiling patterns. J Ultrasound Med. 24(11):1491-1496.

18. de Laat MW, van Alderen ED, Franx A. et al. (2016a): The umbilical coiling index in complicated pregnancy. European Journal of Obstetrics \& Gynecology and Reproductive Biology.;70(12):93- 100.

19. Devaru D and Thusoo M. (2012): Umbilical Coiling Index \& the Perinatal Outcome. J Obstet Gynaecol India; 62(1): 43-46.
This work is licensed under Creative Commons Attribution 4.0 License

To Submit Your Article Click Here: Submit Manuscript

DOI: $10.31579 / 2578-8965 / 088$
Ready to submit your research? Choose Auctores and benefit from:

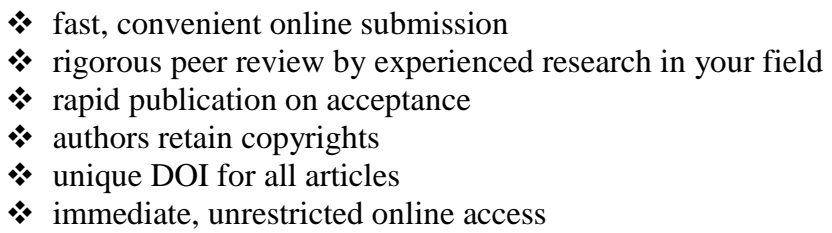

At Auctores, research is always in progress.

Learn more www.auctoresonline.org/journals/obstetrics-gynecology-andreproductive-sciences 